\title{
Memories of the Terrorist Attacks of September 11, 2001: A Study of the Consistency and Phenomenal Characteristics of Flashbulb Memories
}

\author{
Pilar Ferré Romeu \\ Universidad Rovira i Virgili
}

In this study, I investigated students' memories of the terrorist attacks of September 11, 2001, carried out by Al Qaeda terrorists against the World Trade Center in New York and the Pentagon in Washington. Participants completed on two occasions (2 weeks and 8 months after the events took place) a memory questionnaire that included an assessment of the phenomenal richness of their memories. The results showed that the participants remembered very well the circumstances in which they first heard about the terrorist attacks, that they were very confident about this information, and that these memories were characterized by a high phenomenal richness. Over time, there was a decrease in all of these variables, but people's ratings of phenomenology and confidence were still very high. Keywords: flashbulb memories, phenomenal characteristics, confidence, consistency

En este estudio se investigaron los recuerdos que tenían estudiantes de los ataques terroristas del 11 de septiembre de 2001, llevados a cabo por terroristas de Al Qaeda contra el World Trade Center en Nueva York y el Pentágono en Washington. En dos ocasiones diferentes (2 semanas y 8 meses después de los sucesos) los participantes rellenaron un cuestionario de memoria que incluía una evaluación de la riqueza fenomenológica de sus recuerdos. Los resultados mostraron que los participantes recordaban muy bien las circunstancias en las que se enteraron de los ataques terroristas, que tenían mucha confianza en esta información, y que estos recuerdos se caracterizaban por una gran riqueza fenomenológica. Con el paso del tiempo, había un decremento en todas estas variables pero las valoraciones de las personas de la fenomenología y la confianza se mantenían muy altas.

Palabras clave: recuerdos "flashbulb", características fenomenológicas, confianza, consistencia

Correspondence concerning this article should be addressed to Pilar Ferré Romeu. Departamento de Psicología, Universidad Rovira i Virgili, Carretera de Valls, s.n., 43007-Tarragona (Spain). E-mail: pilar.ferre@urv.net 
In a pioneer study, Brown and Kulik (1977) asked people to recall the circumstances in which they first heard of several surprising and impressive events that had taken place between 10 and 30 years earlier (e.g., the death of President John F. Kennedy). They found that most people were able to provide vivid descriptions of these circumstances. Also, some aspects of the circumstances appeared repeatedly in the participants' reports. These included: where the participants were when they first heard the news, what they were doing, who they were with, their own emotional response, other people's emotional responses, the source of the news, and what they did after they heard the news.

Brown and Kulik (1977) used the term "flashbulb memories" to refer to these vivid memories. According to the authors, flashbulb memories are vivid, detailed, and longlasting memories of the circumstances in which people first learned about shocking public events. They also offered the first theoretical explanation for the formation and maintenance of such memories. They hypothesized that flashbulb memories are caused by a special memory mechanism that operates during encoding. They also stated that the kind of events capable of producing flashbulb memories must be new and unexpected, people must consider them important, or the events must have consequences for them. Surprise and consequentiality (which Brown and Kulik equated to emotional arousal) were therefore necessary for the formation of such memories. According to the authors, rehearsal (whether overt-i.e., talking about the event-or coverti.e., thinking about it) also played an important role, as events with a high degree of surprise and consequentiality would be more frequently rehearsed.

Since Brown and Kulik's (1977) work, several studies have tried to identify the encoding and rehearsal factors that contribute to the formation of flashbulb memories. Among these factors are the intensity of people's emotional reactions to the news (Bohannon, 1988; Bohannon \& Symons, 1992; Conway et al., 1994; Curci, Luminet, Finkenauer, \& Gisle, 2001; Davidson \& Glisky, 2002; Hornstein, Brown, \& Mulligan, 2003; Pillemer, 1984; Rubin \& Kozin, 1984; Schmolck, Buffalo, \& Squire, 2000), surprise (Christianson, 1989; Cohen, Conway, \& Maylor, 1994; Conway et al., 1994; Davidson \& Glisky, 2002; Finkenauer et al., 1998; Pillemer, 1984; Rubin \& Kozin, 1984), personal importance (Conway et al., 1994), national importance (Conway et al., 1994; Curci et al., 2001), and rehearsal (Bohannon, 1988; Conway et al., 1994; Curci et al., 2001; Davidson \& Glisky, 2002; Finkenauer et al., 1998; Rubin \& Kozin, 1984).

On the other hand, the involvement of a special memory mechanism in the formation of flashbulb memories has been much debated in the field. Some authors accept such a mechanism (e.g., Pillemer, 1984) and consider flashbulb memories as a distinct class of memories (Conway, 1995). Others consider flashbulb memories to be the result of ordinary memory processes (Christianson, 1989; Curci et al., 2001; Finkenauer et al., 1998; McCloskey, Wible, \&
Cohen, 1988; Neisser, 1982; Neisser \& Harsch, 1992; Neisser et al., 1996). Some of the latter authors stress the importance of rehearsal processes in the formation and maintenance of flashbulb memories (Neisser, 1982; Neisser \& Harsch, 1992; Neisser et al., 1996). According to these authors, the high degree of emotionality of these memories would prompt people to repeat the story. But, as rehearsal is a reconstructive process, it would produce inaccuracies in the participants' report of these memories. Therefore, flashbulb memories would not be formed by any special mechanism. Furthermore, though extremely vivid and recalled with a high degree of confidence, flashbulb memories, like ordinary memories, would be inaccurate and prone to reconstructive processes.

The debate about whether there is a special mechanism for flashbulb memories has been linked to research about the accuracy of such memories. Many studies that have tried to clarify whether flashbulb memories are the result of a special memory mechanism have focused on their pattern of forgetting. This is because of Brown and Kulik's description of flashbulb memories as "photographic pictures." Although these authors never used the word "accuracy" in their paper, it has often been assumed that if a special memory mechanism is involved in the formation of flashbulb memories, these should be highly accurate and immune to forgetting (Conway, 1995).

In most studies, accuracy has been defined as the degree of consistency between memories reported shortly after the event and several months or years later. The level of consistency obtained in these studies has been very variable (see Winningham, Hyman, \& Dinnel, 2000, for a review): Some authors have found high levels of consistency (Bohannon \& Symons, 1992; Cohen et al., 1994; Conway et al., 1994; Hornstein et al., 2003; Pillemer, 1984) while others have reported that, even in flashbulb memories, there is a general loss of specific detailed information over time (Christianson, 1989; Christianson \& Engelberg, 1999; Curci et al., 2001; Schmolck et al., 2000) and that there may be considerable inconsistency between people's recollections at test and retest (McCloskey et al., 1988; Neisser \& Harsch, 1992). Such a loss of information over time is accompanied by a decrease in people's confidence about their recollections (Christianson, 1989). Concerning this discrepancy, Christianson pointed out that not all the information contained in flashbulb memories has to follow the same pattern of forgetting. Therefore, he suggested that some core information present in flashbulb memories is less vulnerable to forgetting, whereas other detailed information is more vulnerable to forgetting over time. Although most studies in the field have not included questions about these two types of information, a recent work of Schmidt (2004) has obtained evidence supporting Christianson's suggestion.

In addition, studies testing the consistency between test and retest have not usually focused on memory for the emotional reaction experienced when one first heard of an 
event. Exceptions are some studies that have obtained mixed results. Christianson and Engelberg (1999) found little consistency over time in people's self-estimations of their emotional reaction. Similarly, Fivush, Edwards, and MennutiWashburn (2003) reported that people tend to underestimate the intensity of their emotional reaction when they heard about a highly negative event. Conversely, Curci et al. (2001) found that, on those occasions, people remember the emotions experienced quite well.

On the other hand, Brown and Kulik (1977) pointed out that one of the most distinctive characteristics of flashbulb memories was that some perceptual and other details of the reception context come to mind with great vividness and clarity. This rich phenomenology might contribute to the high level of confidence that people have in their flashbulb memories, even in cases in which they have been shown to be inaccurate. In fact, some authors have pointed out that the main characteristic of flashbulb memories is not their accuracy, but rather the high degree of confidence participants have in them (Talarico \& Rubin, 2003). Nevertheless, the high phenomenal richness of these memories is a common assumption in flashbulb memory research that has scarcely been tested. There are, however, few studies that have assessed some aspects of flashbulb memories' phenomenal characteristics, such as their overall vividness (Kvavilashvili, Mirani, Schlagman, \& Kornbrot, 2003; Neisser \& Harsch, 1992; Pillemer, 1984; Talarico \& Rubin, 2003; Wright, Gaskell, \& O'Muircheartaigh, 1998), or the amount of visual details (Nachson \& Zelig, 2003; Pillemer, 1984) and other sensory details (Pillemer, 1984) they contain. There is a more detailed way to investigate qualitative characteristics of memories that comes from the literature on source monitoring, the Memory Characteristics Questionnaire (MCQ) developed by Johnson, Foley, Suengas, and Raye (1988). Although it has never been applied to flashbulb memory research, it is beginning to be used by researchers in autobiographical memory. For example, using the MCQ, D'Argembeau, Comblain, and Van der Linden (2003) and Schaefer and Philippot (2005) have reported that emotional autobiographical memories (especially positive ones) are more richly recollected (they contain more sensorial and contextual information) than are neutral memories. If emotional memories are more detailed than neutral ones, we should expect the same pattern of results with flashbulb memories, as they are associated with high levels of emotionality. Thus, the MCQ might be a very useful tool, as it would allow testing with great detail sensorial and contextual characteristics of flashbulb memories.

On September 11, 2001, a series of terrorist attacks shocked almost everyone across the United States and around the world. These events were clearly very appropriate for research in flashbulb memories, as they were surprising, shocking, and probably submitted to a considerable amount of rehearsal. In fact, several studies about flashbulb memories for the September $11^{\text {th }}$ terrorist attacks have recently appeared (Budson et al., 2004; Lee \& Brown, 2003; Luminet et al.,
2004; Niedzwienska, 2004; Pezdek, 2003; Schmidt, 2004; Smith, Bibi, \& Sheard, 2003; Talarico \& Rubin, 2003; Tekcan, Ece, Gülgoz, \& Er, 2003). The present study was also intended to investigate flashbulb memories of the circumstances in which people first heard about the atrocities carried out by Al Qaeda terrorists against the World Trade Center in New York and the Pentagon in Washington on September 11, 2001.

The first aim of the study was to assess the consistency of flashbulb memories over time by collecting data shortly after the 9-11 terrorist attacks took place and 8 months later. If there is a special mechanism involved in the formation of flashbulb memories, one should expect memories of the circumstances in which participants first heard of those events to be very consistent. But, as suggested by Christianson (1989), there might be a different pattern of forgetting for core information and peripheral details. I was interested on testing the consistency of these two kinds of information. With this aim, and following the distinction between central and peripheral features employed by Schmidt (2004), I considered as core information the information that could not be omitted without changing the nature of the event (for example, the place where people were when they first heard the news), whereas peripheral details were those that did not fulfill such a condition (for example, what clothes they were wearing). In addition, I wanted to assess the consistency of people's memories of their emotional reaction when they first heard the news.

A second, and more innovative, aim of this study was to obtain a detailed profile of the phenomenal traits of flashbulb memories. As reviewed in the introduction, this aspect has scarcely been assessed by researchers. I was also interested in testing whether there is a loss of such phenomenal traits over time. If flashbulb memories are a special kind of memories, one might expect them to have a high richness of phenomenal details and that this richness is maintained over time. If this were the case, the rich phenomenology might contribute to the high level of confidence that people have in flashbulb memories, even if they are inaccurate.

\section{Method}

\section{Design}

Memory for the circumstances relating to the 9-11 atrocities was tested two times. The first one, two weeks after the events took place, and the second one, 8 months later. Memory was tested with a questionnaire specially designed for this study. It was modeled on those used by Conway et al. (1994), Curci et al. (2001), and Finkenauer et al. (1998) but it also included an additional set of items intended to assess the phenomenal characteristics of participants' memories. These items were part of the Memory Characteristics Questionnaire elaborated by Johnson et al. (1988). 


\section{Participants}

Thirty-two first year Psychology students participated in the study as a course requirement. Their ages ranged from 18 to 37 years $(M=20.11, S D=2.99)$. They had no knowledge about the topic of flashbulb memories.

\section{Measures}

The test and retest questionnaires were identical. They comprised several sets of questions, which I shall now describe.

Phenomenal characteristics. Participants assessed the phenomenal characteristics of their autobiographical memories of the circumstances in which they first heard about the events. They rated their memories on some of the scales included in the MCQ. Thus, on a 7-point scale (1 = not at all, $7=$ very much), they rated whether their memory of these circumstances was clear, whether it was in color, and whether it contained visual details, sounds, smells, tastes, and tactile sensations. They also rated the degree of vividness and detail of their memory, as well as the ease with which they remembered the circumstances in which they first heard about the events. An average score was calculated for the phenomenal characteristics of participants' memories.

Reception context or flashbulb memory attributes. This set consisted of specific questions about the circumstances in which participants heard the news. They were asked about five aspects of the reception context that, following the Schmidt (2004) criterion, I considered core information: the exact time when they heard the news (date, day of the week, and hour), where they were, what they were doing, who they were with, and what was their source of information. In addition, they were asked about some other detail or peripheral information: what they were wearing, what was their first thought, and what was their activity after hearing the news.

For all questions, participants received a score of 1 when they were able to remember the answer and a score of 0 when they were not. For the question about the date of the event, participants received a score of 2 when their answer included all the information they were asked for. When either the date, the day of the week, or the hour was missing, they scored 1, and when no answer was provided they scored 0 . A core score was calculated by averaging the scores of the five main questions. A peripheral score was computed by averaging the scores of the three remaining questions. In addition, for all the questions, participants rated the degree of confidence about their recollection on a 7-point scale (1 = not at all sure $7=$ completely sure .

Consistency between answers to test and retest was also calculated for all the above questions. The scoring procedure used was modeled on that used by Conway et al. (1994): For each item, responses at the first data collection and at retest were compared. A score of 2 was given if subjects provided exactly the same answer each time, whereas a score of 1 was given when some information was missing or when information changed between test and retest. Finally, a 0 score was given if the answers were totally different or if they were missing at retest. Thus, an average consistency score was computed for both core and peripheral information.

Encoding and rehearsal variables. Participants answered a series of questions about their emotional reactions to the events. On a 7 -point scale $(1=$ no reaction at all; $7=a$ very intense reaction), they had to rate the intensity of their emotional reaction when they first heard the news. Also, on a 7 -point scale $(1=$ not at all; $7=$ very much $)$, they rated the degree to which they experienced the following emotions: anger, sadness, fury, guilt, fear, anxiety, rebelliousness, disgust, shame, and worry.

Participants also rated on a 7 -point scale $(1=$ not at all; $7=$ very much $)$ the extent to which they considered the events to be surprising, the extent to which they thought the events could have consequences for themselves, for Spain, and for the world. On a 7-point scale $(1=$ never, $7=$ more than 10 times), they also rated how often they had followed the news on TV, on the radio, and in the newspapers and how many times they had had spontaneous thoughts, memories or images about the events since they took place.

\section{Procedure}

Two weeks after the 9-11 attacks, participants were given the initial questionnaire. They were not told about any future retest. Eight months later, they were given the same questionnaire to retest their memories. Both questionnaires were answered during a classroom session. A short introduction to the questionnaires indicated that there were no right or wrong answers to any question and that the study was concerned with memory for impacting events.

\section{Results}

Questionnaire scores obtained at test, mean consistency values between test and retest for the reception context questions, and participants' confidence ratings are shown in Table 1. The data show that core information was better remembered than peripheral details, $t(31)=2.6, p<.05$, and that participants were more confident about their responses to the core questions than to the peripheral ones, $t(22)=3.2, p<.01$. Furthermore, as can be seen from the table, the degree of consistency was not the same for all the questions. In particular, the highest consistency ratings were for the questions included in the core information category, whereas those belonging to the peripheral category showed a lower consistency level, $t(23)=6.2, p<.001$. Confidence ratings also decreased for some of the questions between test and retest. In particular, there was a significant decrease in participants' confidence about their memory for time, $t(31)=3.3, p<.005$, place, $t(30)=3.2, p<.005$, other people present. $t(31)=2.5, p<.05$, their activity after 
hearing the news, $t(28)=4.1, p<.001$, and their first thought, $t(31)=3.7, p<.005$. In addition, when I analyzed participants' confidence about their memories for core and peripheral information, I observed that, in both cases, there was a decrease between test and retest, $t(31)=3.7, p<.005$ and $t(31)=4.7, p<.001$, respectively. However, the decrease in confidence was larger for peripheral details than for core information, $t(16)=-2.6, p<.05$.

The phenomenal and emotional characteristics of memories reported at test and retest are shown in Table 2.
Concerning the first test, a repeated measures ANOVA showed that there were differences between the different phenomenal characteristics assessed, $F(9,23)=109.6, p<$ .001. In particular, memories' clarity and the ease with which people remembered the circumstances in which they first heard about the events received the highest scores. A further repeated measures ANOVA showed that there were differences between the ratings of the different emotions, $F(9,23)=40.9, p<.001$. As can be seen from the table, worry was the most intensely experienced emotion.

Table 1

Participants' Mean Responses at Test and Retest: Reception Context and Confidence

\begin{tabular}{|c|c|c|c|c|}
\hline Variables & Test scores & Confidence & Consistency scores & Confidence \\
\hline Time & $1.8(0.1)$ & $6.5(0.1)$ & $1.6(0.1)$ & $5.7(0.3)$ \\
\hline Place & $1.0(0.0)$ & $6.9(0.1)$ & $1.8(0.1)$ & $6.4(0.1)$ \\
\hline Ongoing activity & $1.0(0.0)$ & $6.8(0.1)$ & $1.6(0.1)$ & $6.4(0.2)$ \\
\hline Other people present & $1.0(0.0)$ & $6.9(0.1)$ & $1.6(0.1)$ & $6.6(0.1)$ \\
\hline Source & $1.0(0.0)$ & $6.8(0.1)$ & $1.8(0.1)$ & $6.6(0.1)$ \\
\hline Clothes & $0.7(0.1)$ & $4.9(0.4)$ & $1.2(0.2)$ & $4.5(0.4)$ \\
\hline First thought & $1.0(0.0)$ & $6.3(0.2)$ & $0.8(0.2)$ & $5.0(0.3)$ \\
\hline Activity after hearing the news & $0.9(0.0)$ & $6.8(0.1)$ & $1.3(0.2)$ & $5.7(0.2)$ \\
\hline Core information & $1.0(0.0)$ & $6.8(0.0)$ & $1.7(0.0)$ & $6.4(0.1)$ \\
\hline Peripheral information & $0.9(0.0)$ & $5.9(0.2)$ & $1.1(0.1)$ & $5.1(0.2)$ \\
\hline
\end{tabular}

Note. Standard errors of the mean are in parentheses.

Table 2

Means of Phenomenal Ratings and Emotional Ratings at Test and Retest

\begin{tabular}{|c|c|c|}
\hline Variables & Test & Retest \\
\hline Phenomenal traits (average score) & $4.6(0.1)$ & $4.3(0.2)$ \\
\hline Clarity & $6.6(0.1)$ & $5.6(0.2)$ \\
\hline Colors & $5.9(0.2)$ & $5.8(0.2)$ \\
\hline Visual details & $6.0(0.2)$ & $5.6(0.2)$ \\
\hline Sounds & $4.6(0.3)$ & $4.1(0.3)$ \\
\hline Smells & $1.5(0.2)$ & $1.8(0.2)$ \\
\hline Tastes & $1.6(0.2)$ & $2.0(0.3)$ \\
\hline Tactile sensations & $2.2(0.3)$ & $2.4(0.3)$ \\
\hline Vividness & $6.0(0.2)$ & $0.9(0.2)$ \\
\hline Detail & $5.6(0.2)$ & $4.8(0.3)$ \\
\hline Ease in remembering & $6.6(0.1)$ & $5.5(0.3)$ \\
\hline Intensity of emotional reaction & $5.5(0.2)$ & $5.5(0.2)$ \\
\hline Anger & $3.1(0.3)$ & $3.7(0.3)$ \\
\hline Sadness & $5.7(0.2)$ & $5.1(0.3)$ \\
\hline Fury & $4.2(0.4)$ & $4.4(0.3)$ \\
\hline Guilt & $1.2(0.1)$ & $1.5(0.2)$ \\
\hline Fear & $3.9(0.4)$ & $4.1(0.4)$ \\
\hline Anxiety & $4.0(0.4)$ & $3.7(0.3)$ \\
\hline Rebelliousness & $2.5(0.3)$ & $2.9(0.3)$ \\
\hline Disgust & $2.3(0.4)$ & $2.8(0.4)$ \\
\hline Shame & $1.5(0.2)$ & $1.6(0.2)$ \\
\hline Worry & $6.3(0.2)$ & $5.8(0.2)$ \\
\hline
\end{tabular}

Note. Standard errors of the mean are in parentheses. 
I performed $t$-tests to analyze differences between test and retest ratings. These tests showed that there were significant differences in clarity of memories, $t(31)=4.5$, $p<.001$, the degree of memories' visual detail, $t(31)=4.8$, $p<.001$, ease in remembering, $t(31)=4.3, p<.001$, the detail of participants' memories, $t(31)=3.5, p<.005$, and their vividness, $t(31)=4.8, p<.001$. Furthermore, there was a significant difference in the average score for the phenomenal characteristics of participants' memories, $t(31)$ $=3.1, p<.005$. With regard to emotional intensity, the scores at test and retest were identical. Concerning the specific emotions, the only significant differences between test and retest appeared for anger, $t(30)=-2.3, p<.05$, sadness $t(31)$ $=2.6, p<.05$, and worry, $t(31)=3.3, p<.005$.

Finally, I performed several Pearson correlations between the encoding and rehearsal variables, the participants' memories phenomenal characteristics, and the reception context variables. The most relevant correlations were the following: The average score for the phenomenal traits of participants' memories correlated with the intensity of their emotional reaction, $r=.55, p<.005$, with the degree of surprise of the events, $r=.50, p<.005$, with the extent to which they could have consequences for the participants, $r$ $=.51, p<.005$, for Spain, $r=.53, p<.005$, and for the world, $r=.51, p<.005$, and with the frequency with which participants had followed the news on TV, $r=.40, p<.05$. The intensity of participants' emotional reaction correlated with the extent to which the events could have consequences for themselves, $r=.50, p<.005$, for Spain $r=.44, p<.05$, and for the world, $r=.65, p<.001$, with the extent to which they were surprising, $r=.37, p<.05$, and with the extent to which participants talked about the feelings related to the events, $r=.36, p<.05$. Furthermore, there was a significant correlation between the extent to which the events were surprising and how often participants had followed the news on TV, $r=.39, p<.05$, how many times they had had spontaneous thoughts about the events, $r=.37, p<.05$, the extent to which they had talked about the reception context, $r=.44, p<.05$, and the extent to which the events could have consequences for the world, $r=.39, p<.05$. However, I failed to obtain any significant correlation between reception context measures and any of the encoding and rehearsal variables. I did not observe either any significant correlation between participants' confidence in their memories, the phenomenal characteristics of these memories, and their test-retest consistency.

\section{Discussion}

In this study, I examined people's memories of the circumstances in which they first heard about the terrorist attacks of September 11, 2001. I also examined the phenomenal traits of these memories and the degree of confidence that participants had in them. In addition, I tested the consistency of these memories over time. The results show that participants were able to remember a lot of information about the reception context of the 9-11 terrorist attacks, they were very confident about this information, and that these memories were characterized by a high phenomenal richness. Over time, there was a general loss of information and a decrease in participants' confidence in their recollections that affected peripheral details more than core information. Furthermore, there was a reduction in the phenomenal richness of participants' memories. In spite of this decrease, people's recollections of the September $11^{\text {th }}$ terrorist attacks at retest were still very rich and participants continued to be very confident about them. Finally, 8 months after the events took place, participants remembered very well the intensity of their emotional reactions when they first heard about the news.

As stated at the end of the introduction, the most innovative aim of the present study was to obtain a detailed profile of the phenomenal characteristics of memories for highly emotional and unexpected events. To my knowledge, this study is the first one in this field of research that has tested flashbulb memories' phenomenology in such a detailed way. These results show that flashbulb memories contain a high richness of phenomenal details and that they are especially characterized by their clarity and the ease in remembering them. Furthermore, although the circumstances in which participants heard about the September $11^{\text {th }}$ terrorist attacks were more richly recollected at the first test than at retest, participants' memories retained a high degree of sensorial details and continued to be easy to remember 8 months after the events took place. These findings are in the same line of some previous studies that have reported that flashbulb memories are vividly recollected (e.g., Kvavilashvili et al., 2003; Talarico \& Rubin, 2003). Wright et al. (1998), however, did not obtain high levels of vividness in their study. This last result might be due to the fact that the authors assessed vividness of the memories, which, according to my results, is not the most distinctive trait of flashbulb memories. Furthermore, they interviewed participants a long time after the events took place (19 and 38 months). In fact, as we have just seen, my own findings show that there is some decrease in flashbulb memories' phenomenal traits over time.

On the other hand, these results concerning flashbulb memories' phenomenal traits are in agreement with previous work that has shown that emotional memories are more richly recollected than neutral ones (D'Argembeau et al., 2003; Schaefer \& Philippot, 2005). Whereas in these studies, this superiority has been especially obtained with positive events, my results show that it can also be observed with negative events, when they produce a high emotional reaction. It could be that the lack of effects with negative information in previous studies was due to the fact that they had not a high degree of emotional intensity.

The test-retest methodology has also allowed me to assess whether participants remember accurately the intensity 
of their feelings when the events took place. This is a topic scarcely addressed in research about flashbulb memories. I observed that people remember quite well the intensity of their emotional reactions to a shocking and impressive event. These results are in agreement with those of Curci et al. (2001) but contrast with the findings of Fivush et al. (2003), who observed that people did not accurately recall the intensity of their feelings when they first heard about the 9-11 terrorist attacks. These contradictory data could be explained, from my point of view, by methodological reasons, such as the procedure employed to assess emotionality: Fivush et al. used a global measure of emotional stress, whereas the present study and the one by Curci et al. included assessments of global emotional intensity as well as of different types of emotions.

Concerning memories of the reception context, the present findings show that not all the items were equally remembered, since there was superiority in memory for core information over peripheral information. This superiority was also evident in participants' confidence. Moreover, the differences between core and peripheral information were maintained over time, since my data show that, although there was a general loss of information in the 8 months elapsed between test and retest, the degree of consistency of memories for core information was greater than for peripheral information. The same was true for participants' confidence in their recollections. From my point of view, these findings suggest that the distinction between core and peripheral information proposed by Christianson (1989) is a relevant one. It might be that previous discrepancies between studies assessing flashbulb memories' consistency over time could be explained by the reception context variables tested. My results clearly suggest that flashbulb memories contain some information that, although thought vulnerable to the passage of time, is more resistant to forgetting than other details that are initially included in participants' reports of the circumstances in which they first heard about the news. This higher resistance to forgetting is accompanied by a greater confidence.

However, it has to be taken into account that, even in the case of core information, I failed to obtain a perfect consistency between test and retest. This result is in agreement with previous flashbulb memory research that has reported an overall loss of information over time (Christianson, 1989; Christianson \& Engelberg, 1999; Curci et al., 2001; Lee \& Brown, 2003; McCloskey et al., 1988; Neisser \& Harsch, 1992; Schmidt, 2004; Schmolk et al., 2000; Talarico \& Rubin, 2003; Tekcan et al., 2003). In addition, the finding that peripheral details seem to be submitted to a higher forgetting rate over time than is core information is in the same line as the two previous studies that have assessed consistency for central and peripheral information in flashbulb memories (Christianson, 1989; Schmidt, 2004). According to Schmidt, these results would suggest that flashbulb memories are not like photographs.
Rather, people would retain schematic information about the circumstances in which they heard about the news, but their memories for peripheral details would be poor.

My data with respect to memories of the reception context of shocking and impressive events as well as those concerning the phenomenal characteristics of these memories suggest that they are not immune to forgetting and that, with the passage of time, they undergo some loss of their phenomenal richness. These findings could be considered as evidence against the involvement of a special mechanism in the formation of flashbulb memories. However, it has to be taken into account that, in spite of these decreases, people's ratings of phenomenology and confidence were still very high and that there are some aspects of the reception context that were very well remembered 8 months after the events took place. Moreover, there is a limitation in the present study that precludes the establishment of clear conclusions about the special status of flashbulb memories: I did not include a control event. If I had assessed participants' memories of some other autobiographical event and had compared them with their memories of the September $11^{\text {th }}$ terrorist attacks, I could arrive at stronger conclusions. Without such a control, my data have to be considered descriptive.

Finally, I would like to point out that several authors have tried to identify the encoding and rehearsal factors that contribute to the formation of flashbulb memories. These variables are the intensity of people's emotional reactions to the news (Bohannon, 1988; Bohannon \& Symons, 1992; Brown \& Kulik, 1977; Conway et al., 1994; Curci et al., 2001; Davidson \& Glisky, 2002; Hornstein et al., 2003; Pillemer, 1984; Rubin \& Kozin, 1984; Schmolk et al., 2000), the extent to which the news was surprising (Christianson, 1989; Cohen et al., 1994; Conway et al., 1994; Davidson \& Glisky, 2002; Finkenauer et al., 1998; Pillemer, 1984; Rubin \& Kozin, 1984) and submitted to rehearsal (Bohannon, 1988; Conway et al., 1994; Curci et al., 2001; Davidson \& Glisky, 2002; Finkenauer et al., 1998; Hornstein et al., 2003; Rubin \& Kozin, 1984), as well as the degree of personal and national importance of the event (Conway et al., 1994; Curci et al., 2001). The correlational analyses performed failed to show any significant relationship between any of these variables and participants' memories of the reception context. I did not obtain either any significant correlation between the memories' phenomenal traits, their test-retest consistency, and the degree of confidence that participants had in their memories. In my opinion, the failure to obtain more relevant correlations could be due to the low number of participants in this study. Nevertheless, it has to be pointed out that I have obtained a relevant pattern of relationships: My data show that there is a correlation between the degree of surprise of the events, the intensity of the emotional reaction they provoked, their consequentiality, the extent to which they were submitted to some kind of rehearsal, and the degree of phenomenal richness of memories of the circumstances in 
which people first heard about the events. These results suggest that there is a clear relationship between some of the traits that characterize flashbulb memories, such as that they are rich in phenomenal details and that they are produced by surprising, emotionally arousing, consequential, and rehearsed events.

To sum up, these results suggests that the September $11^{\text {th }}$ terrorist attacks produced an intense emotional reaction also in people from countries other than the United States, such as Spain, that they were surprising, consequential, and submitted to an important degree of rehearsal. People had detailed and phenomenally rich memories of the circumstances in which they first heard about the terrorist attacks. However, these memories were not immune to forgetting as there was a decrease in information, in phenomenal details, and in people's confidence over time. Further research, including larger samples of participants, should be addressed to compare the rate of forgetting and the phenomenal traits of memories of impressive and shocking events with those of more ordinary autobiographical events.

\section{References}

Bohannon, J.N. (1988). Flashbulb memories for the space shuttle disaster: A tale of two theories. Cognition, 29, 179-196.

Bohannon, J.N., \& Symons, V.L. (1992). Flashbulb memories: Confidence, consistency, and quantity. In E. Winograd \& U. Neisser (Eds.), Affect and accuracy in recall: Studies of 'flashbulb memories' (pp. 69-94). Cambridge: Cambridge University Press.

Brown, R., \& Kulik, J. (1977). Flashbulb memories. Cognition, 5, 73-99.

Budson, A.E., Simons, J.S., Sullivan, A.L., Beier, J.S., Solomon, P.R., Scinto, L.F., Daffner, K.R., \& Schacter, D.L. (2004). Memory and emotions for the September 11, 2001, terrorist attacks in patients with Alzheimer's disease, patients with mild cognitive impairment, and healthy older adults. Neuropsychology, 18, 315-327.

Christianson, S.A. (1989). Flashbulb memories: Special, but not so special. Memory \& Cognition, 17, 435-443.

Christianson, S.A., \& Engelberg, E. (1999). Memory and emotional consistency: The MS Estonia ferry disaster. Memory, 7, 471482.

Cohen, G., Conway, M.A., \& Maylor, E.A. (1994). Flashbulb memories in older adults. Psychology and Aging, 9, 454-463.

Conway, M.A. (1995). Flashbulb memories. Hove, UK: Erlbaum.

Conway, M.A., Anderson, S.J., Larsen, S.F., Donnelly, C.M., McDaniel, M.A., McClelland, A.G.R., Rawles, R.E., \& Logie, R.H. (1994). The formation of flashbulb memories. Memory \& Cognition, 22, 326-343.

Curci, A., Luminet, O., Finkenauer, C., \& Gisle, L. (2001). Flashbulb memories in social groups: A comparative test-retest study of the memory of French President Mitterrand's death in a French and a Belgian group. Memory, 9, 81-101.
Davidson, P.S.R., \& Glisky, E.L. (2002). Is flashbulb memory a special instance of source memory? Evidence from older adults. Memory, 10, 99-111.

D’Argembeau, A., Comblain, C., \& Van der Linden, M. (2003). Phenomenal characteristics of autobiographical memories for positive, negative, and neutral events. Applied Cognitive Psychology, 17, 281-294.

Finkenauer, C., Luminet, O., Gisle, L., El-Ahmadi, A., Van der Linden, M., \& Philippot, P. (1998). Flashbulb memories and the underlying mechanisms of their formation: Toward an emotionalintegrative model. Memory \& Cognition, 26, 516-531.

Fivush, R., Edwards, V.J., \& Mennuti-Washburn, J. (2003). Narratives of 9/11: Relations among personal involvement, narrative content and memory of the emotional impact over time. Applied Cognitive Psychology, 17, 1099-1111.

Hornstein, S.L., Brown, A.S., \& Mulligan, N.W. (2003). Longterm flashbulb memory for learning of Princess Diana's death. Memory, 11, 293-306.

Johnson, M.K., Foley, M.A., Suengas, A.G., \& Raye, C.L. (1988). Phenomenal characteristics of memories for perceived and imagined autobiographical events. Journal of Experimental Psychology: General, 117, 371-376.

Kvavilashvili, L., Mirani, J., Schlagman, S., \& Kornbrot, D.E. (2003). Comparing flashbulb memories of September 11 and the death of Princess Diana: Effects of time delays and nationality. Applied Cognitive Psychology, 17, 1017-1031.

Lee, P.J., \& Brown, N.R. (2003). Delay related changes in personal memories for September 11, 2001. Applied Cognitive Psychology, 17, 1007-1015.

Luminet, O., Curci, A., Marsh, E.J., Wessel, I., Constantin, C., Gencoz, F., \& Yogo, M. (2004). The cognitive, emotional, and social impacts of the September 11 attacks: Group differences in memory for the reception context and the determinants of flashbulb memory. The Journal of General Psychology, 13, 197-224.

McCloskey, M., Wible, C.G., \& Cohen, N.J. (1988). Is there a special flashbulb memory mechanism? Journal of Experimental Psychology, 117, 171-181.

Nachson, I., \& Zelig, A. (2003). Flashbulb and factual memories: The case of Rabin's assassination. Applied Cognitive Psychology, 17, 519-531.

Neisser, U. (1982). Snapshots or benchmarks? In U. Neisser (Ed.), Memory observed (pp. 43-48). San Francisco: Freeman.

Neisser, U., \& Harsch, N. (1992). Phantom flashbulbs: False recollections of hearing the news about Challenger. In E. Winograd \& U. Neisser (Eds.), Affect and accuracy in recall: Studies of "flashbulb memories" (pp. 9-31). New York: Cambridge University Press

Neisser, U., Winograd, E., Bergman, E.T., Schreiber, C.A., Palmer, S.E., \& Weldon, M.S. (1996). Remembering the earthquake: Direct experience vs. hearing the news. Memory, 4, 337-357.

Niedzwienska, A. (2004). Metamemory knowledge and the accuracy of flashbulb memories. Memory, 12, 603-613.

Pezdek, K. (2003). Event memory and autobiographical memory for the events of September 11, 2001. Applied Cognitive Psychology, 17, 1033-1045. 
Pillemer, D.B. (1984). Flashbulb memories of the assassination attempt on President Reagan. Cognition, 16, 63-80.

Rubin, D.C., \& Kozin, M. (1984). Vivid memories. Cognition, 16, 81-95.

Schaefer, A., \& Philippot, P. (2005). Selective effects of emotion on the phenomenal characteristics of autobiographical memories. Memory, 13, 148-160.

Schmidt, S.R. (2004). Autobiographical memories for the September $11^{\text {th }}$ attacks: Reconstructive errors and emotional impairment of memory. Memory and Cognition, 32, 443-454.

Schmolck, H., Buffalo, E.A., \& Squire, L.R. (2000). Memory distortions develop over time: Recollections of the O.J. Simpson trial verdict after 15 and 32 months. Psychological Science, 11, 39-45.

Smith, M.C., Bibi, U., \& Sheard, E. (2003). Evidence for the differential impact of time and emotion on personal and event memories for September 11, 2001. Applied Cognitive Psychology, 17, 1047-1055.
Talarico, J.M., \& Rubin, D.C. (2003). Confidence, not consistency, characterizes flashbulb memories. Psychological Science, 14, 455-461.

Tekcan, A.I., Ece, B., Gülgöz, S., \& Er, N. (2003). Autobiographical and event memory for 9/11: Changes across one year. Applied Cognitive Psychology, 17, 1057-1066.

Winningham, R.G., Hyman, I.E., \& Dinnel, D.L. (2000). Flashbulb memories? The effects of when the initial memory report was obtained. Memory, 8, 209-216.

Wright, D., Gaskell, G.D., \& O’Muircheartaigh, C. (1998). Flashbulb memory assumptions: Using national surveys to explore cognitive phenomena. British Journal of Psychology, 89, 103-122.
Received, May, 24, 2005

Review received, July, 22, 2005 Accepted September 15, 2005 